\title{
Resonant Parametric Perturbation Method to Control Chaos in Current Mode Controlled DC-DC Buck-Boost Converter
}

\author{
Anbukumar Kavitha ${ }^{\dagger}$ and Govindarajan Uma*
}

\begin{abstract}
Resonant parametric perturbation (RPP) method is an effective non-feedback method for controlling chaos. In this paper, the above method is applied for the current programmed buck-boost dc-dc converter which exhibits chaotic for wide parameter variations. The different possible operating regimes leading to chaotic operation of the current mode controlled buck-boost converter is discussed and the control of chaos by RPP method is demonstrated through computer simulations and experimental studies. The converter is stabilized to period 1 operation practically.
\end{abstract}

Keywords: Buck-boost Converter, Chaos, DC-DC converter, Resonant parametric perturbation

\section{Introduction}

Chaotic behavior has been identified in many physical and engineering systems. Power electronics is a field rich in nonlinear dynamics, and engineers who work in this field are frequent "chaos observers" [1]. During the early development and testing stages of power electronics systems, a multitude of nonlinear phenomena, such as sub harmonics, quasi-periodicity and chaos, are observed [2]. Because power electronics engineers are primarily concerned with only the regular periodic (fixed point) operation, they tend to avoid any "strange" operation by adjusting components or parameters that they believe are causing problems to their systems [3]. Because of the unpredictable or sometimes undesirable consequences chaos causes in the systems, control of chaos has now become a topic of interest.

Recently many chaos control methods have been proposed for various applications [4]. Their objectives fall into two general categories. In the first category, one of the unstable periodic orbits within a chaotic attractor is first identified as the control target, and control action is directed to stabilize the system so that it settles on the target periodic orbit. In the second category, a desired operating state is the control target, which need one be those unstable orbits embedded in the chaotic attractor. Here, the control action is to achieve the desired operating state. The first type of control objective is usually achieved by feedback methods, whereas the second type can be accomplished by nonfeedback methods. Examples of feedback methods include the Ott Grebogi Yorke (OGY) method, occasional proportional feedback (OPF) method, time-delayed feedback control method (TDFC) etc. In these methods, system variables are measured, a control law implemented and some control

$\dagger$ Corresponding Author: Dept. of Electrical and Electronic Engineering, College of Engineering Guindy, Anna University, Chennai, Tamilnadu, India. (akavitha@annauniv.edu)

* Dept. of Electrical and Electronic Engineering, College of Engineering Guindy, Anna University, Chennai, Tamilnadu, India.

(uma@annauniv.edu)

Received : September 2, 2009; Accepted : February 4, 2010 parameters varied to achieve the required control objective. On the other hand, for the non-feedback type of control, no system variables need to be measured and no specific periodic orbit has to be identified as the control target. Examples of non-feedback methods include adaptive control, resonant parametric perturbation, weak perturbation entrainment and migration control, etc. Compared to feedback methods, non-feedback methods are simpler and suited for practical implementations [5].

Attention in this paper is focused on the non-feedback type of control for controlling chaos. In particular, the resonant parametric perturbation method is considered. This technique is highly suitable for controlling chaos in periodically driven systems, despite the fact that it requires nonzero control power even when the system has been controlled to its steady state [6]. In this paper, a current controlled dc-dc buck boost converter is considered and the application of resonant parametric perturbation for suppressing chaos is illustrated. Analysis and simulations are presented to show that an unstable period 1 orbit in the chaotic attractor is stabilized and the experimental results provide evidences for the proposed control method.

\section{Analysis of DC-DC Buck-Boost Converter}

The circuit diagram of dc-dc buck-boost converter operating in continuous mode is shown in Fig. 1. Here $\mathrm{S}$ is the power switch and $\mathrm{D}_{1}$ is the freewheeling diode. The switch is driven by a Pulse Width Modulated (PWM) switching signal with frequency $f_{s}$ and duty ratio $D$. The energy storage elements are inductor $\mathrm{L}$, and capacitor $\mathrm{C}$. $\mathrm{R}$ is the load resistance. $V_{\text {in }}$ and $V_{o}$ are the input and average output voltages respectively.

To analyze the steady state behaviour, each switching cycle is divided into two modes. The equivalent circuit for each mode is shown in Fig. 2. 


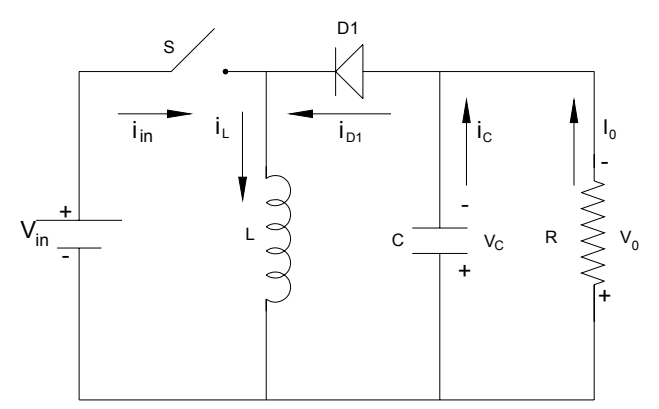

Fig. 1 Circuit diagram of buck-boost converter.

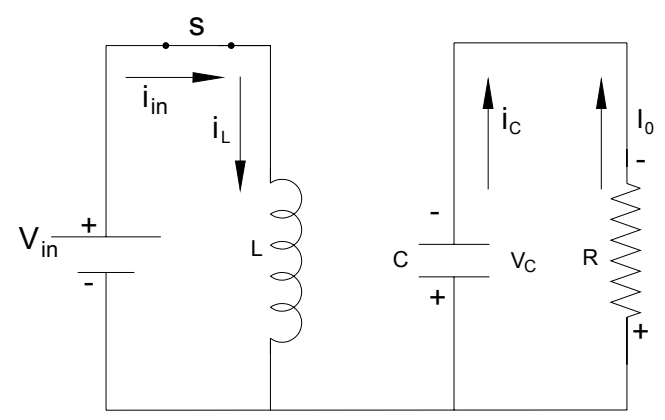

(a)

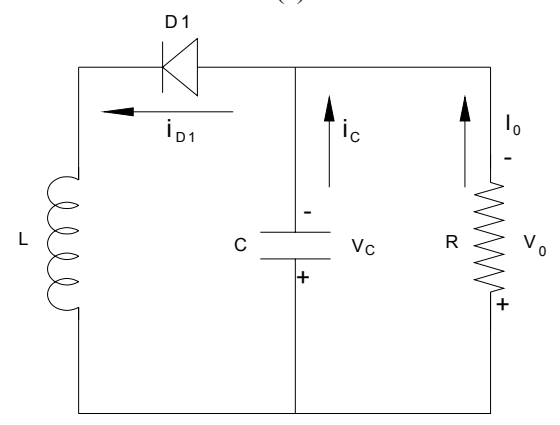

(b)

Fig. 2. Equivalent circuit of the buck-boost converter during (a) Mode 1 (b) Mode 2.

\subsection{Mode 1 Operation: $(0 \leq \mathrm{t}<$ DT)}

This mode starts at $\mathrm{t}=0$, when the switch $\mathrm{S}$ is $\mathrm{ON}$ and the diode $\mathrm{D}_{1}$ is OFF. The inductor $\mathrm{L}$ absorbs energy from the source. The stored energy in capacitor $\mathrm{C}$ is delivered to load R. $i_{L}$ increases linearly during this mode and the source current is the inductor current $\mathrm{i}_{\mathrm{L}}$. During the ON period, the system matrices are given by

$$
A_{1}=\left[\begin{array}{cc}
\frac{-1}{C R} & 0 \\
0 & 0
\end{array}\right] B_{1}=\left[\begin{array}{c}
0 \\
\frac{1}{L}
\end{array}\right]
$$

\subsection{Mode 2 Operation: $\left(t_{1}=D T \leq t<T\right)$}

At $\mathrm{t}=\mathrm{t}_{1}$, the switch $\mathrm{S}$ is turned OFF. Since the current in the inductor cannot change instantaneously, the voltage across the inductor reverses its polarity in an attempt to maintain a constant current. The current, which was flowing through the switch, now flows through $\mathrm{L}, \mathrm{C}, \mathrm{D}_{1}$ and the load. The inductor current decreases until the switch $\mathrm{S}$ is turned on again for the next cycle. The inductor delivers its stored energy to the output capacitor $\mathrm{C}$ and charges it up via diode. This energy supplies the load current and replenishes the charge drained away from the output capacitor. The system matrices during OFF period are given by

$$
\mathrm{A}_{2}=\left[\begin{array}{cc}
\frac{-1}{\mathrm{CR}} & \frac{1}{\mathrm{C}} \\
\frac{-1}{\mathrm{~L}} & 0
\end{array}\right] \quad \mathrm{B}_{2}=\left[\begin{array}{l}
0 \\
0
\end{array}\right]
$$

If $\mathrm{V}_{\text {in }}$ and $\mathrm{I}_{\text {in }}$ are the average input voltage and current respectively then, the voltage transfer gain in continuous mode is given by $\frac{V_{0}}{V_{\text {in }}}=\frac{I_{\text {in }}}{I_{0}}=\frac{-D}{1-D}$.

\section{Discrete Model of the Converter}

To analyze the chaotic behaviour, the discrete model of the converter is considered. A two dimensional mapping is derived which describes the behaviour of a current-mode controlled buck-boost converter, which is found to exhibit sub harmonic instability and chaos [7]. The mapping is a function that relates the capacitor voltage and current vector $\left(v_{n+1}, i_{n+1}\right)$ sampled at one instant, to the vector $\left(v_{n}, i_{n}\right)$ at the previous instant.

The mapping is iterated numerically to give a rapid quantitative summary of the behaviour of the circuit and the bifurcations are analyzed. The waveforms of inductor current $\mathrm{i}_{\mathrm{L}}$ and capacitor voltage $\mathrm{v}_{\mathrm{o}}$ are given in Fig. 3 .

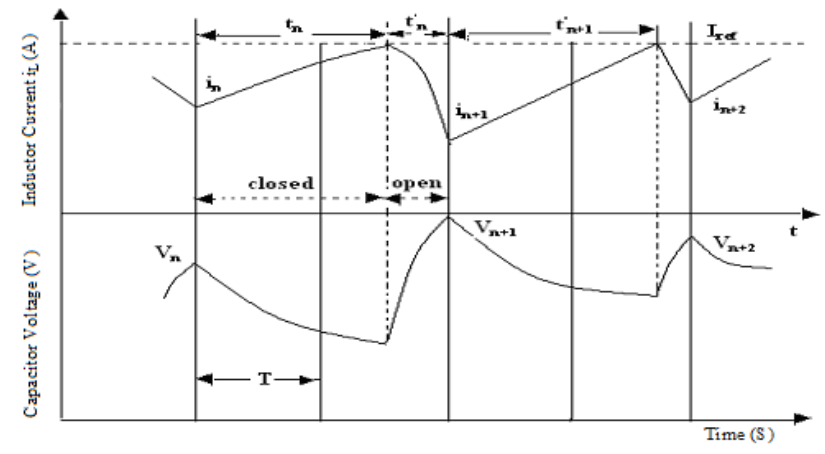

Fig. 3. Inductor current and capacitor voltage waveforms.

\subsection{Switch S Closed}

When switch $\mathrm{S}$ is closed, diode $\mathrm{D}_{1}$ blocks at $\mathrm{t}=0$ and the circuit is described by two first-order differential equations which are given as follows,

$$
\frac{\mathrm{di}_{\mathrm{L}}}{\mathrm{dt}}=\frac{\mathrm{V}_{\text {in }}}{\mathrm{L}}
$$




$$
\frac{\mathrm{dv}_{\mathrm{c}}}{\mathrm{dt}}=-\frac{1}{\mathrm{RC}} \mathrm{v}_{\mathrm{c}}
$$

Assuming the initial inductor current $i_{L}=i_{n}$, the capacitor voltage $\mathrm{v}_{\mathrm{c}}=\mathrm{v}_{\mathrm{n}}$ and $\mathrm{i}_{\mathrm{L}}=\mathrm{I}_{\text {ref }}$ at time $\mathrm{t}=\mathrm{t}_{\mathrm{n}}$, the solution of above equation are given by,

$$
\begin{gathered}
\mathrm{t}_{\mathrm{n}}=\frac{\mathrm{L}}{\mathrm{V}_{\text {in }}}\left(\mathrm{I}_{\text {ref }}-\mathrm{i}_{\mathrm{n}}\right) \\
\mathrm{V}_{\mathrm{c}}\left(\mathrm{t}_{\mathrm{n}}\right)=\mathrm{v}_{\mathrm{n}} \mathrm{e}^{\frac{-\mathrm{t}_{\mathrm{n}}}{\mathrm{RC}}}
\end{gathered}
$$

where $t_{n}$ is the time at which switch opens.

\subsection{Switch S Open}

When $\mathrm{S}$ is opened, $\mathrm{D}_{1}$ conducts and the circuit is described by two first-order differential equations.

$$
\begin{gathered}
\frac{\mathrm{di}_{\mathrm{L}}}{\mathrm{dt}}=-\frac{1}{\mathrm{~L}} \mathrm{v}_{\mathrm{c}} \\
\frac{\mathrm{dv}_{\mathrm{c}}}{\mathrm{dt}}=\frac{1}{\mathrm{C}} \mathrm{i}_{\mathrm{L}}-\frac{1}{\mathrm{RC}} \mathrm{v}_{\mathrm{c}}
\end{gathered}
$$

The circuit is described by these equations until the next clock pulse arrives, causing $\mathrm{S}$ to close. This happens for duration $t_{n}^{\prime}=T\left[1-\frac{t_{n}}{T}\right]$. The values of $i_{n+1}$ and $v_{n+1}$ at the next clock instant are solved from equations (7) and (8) with $I_{\text {ref }}$ and $v_{n} e^{\frac{-t_{n}}{R C}}$ as initial values. The general solution of the equation (7) is

$$
\mathrm{i}_{\mathrm{L}}\left(\mathrm{t}_{\mathrm{n}}^{\prime}\right)=\mathrm{e}^{\alpha \mathrm{t}_{\mathrm{n}}^{\prime}}\left(\mathrm{c}_{1} \cos \beta \mathrm{t}_{\mathrm{n}}^{\prime}+\mathrm{c}_{2} \sin \beta \mathrm{t}_{\mathrm{n}}^{\prime}\right)
$$

where

$$
\alpha=-\frac{1}{2 \mathrm{RC}}, \quad \beta=\frac{1}{2 \mathrm{RC}} \sqrt{\frac{4 \mathrm{R}^{2} \mathrm{C}}{\mathrm{L}}-1}
$$

The constants $c_{1}$ and $c_{2}$ are set by boundary conditions. Setting $t=0$ immediately after $\mathrm{S}$ has opened the values of $\mathrm{c}_{1}$ and $\mathrm{c}_{2}$ are determined by substituting initial conditions as follows,

$$
\mathrm{i}_{\mathrm{L}}(0)=\mathrm{c}_{1}=\mathrm{I}_{\text {ref }} ; c_{1}=\mathrm{I}_{\text {ref }}
$$

Using $\mathrm{i}_{\mathrm{L}}(\mathrm{t})$ from equation (9) and solving gives,

$$
c_{2}=-\frac{1}{\beta}\left(\frac{v_{n} e^{\frac{t_{n}}{R C}}}{L}+I_{r e f} \alpha\right)
$$

Now by definition $i_{n+1}=i_{L}\left(t_{n}{ }^{\prime}\right)$. Hence substituting for $t_{n}{ }^{\prime}$ in equation (9) provides $i_{n+1}$ as follows,

$$
i_{n+1}=e^{\alpha\left(T-t_{n}\right)}\left(c_{1} \cos \beta\left(T-t_{n}\right)+c_{2} \sin \beta\left(T-t_{n}\right)\right)
$$

where

$$
c_{1}=\mathrm{I}_{\text {ref }}, c_{2}=-\frac{1}{\beta}\left(\frac{\mathrm{v}_{\mathrm{n}} \mathrm{e}^{\frac{\mathrm{t}_{\mathrm{n}}}{\mathrm{RC}}}}{\mathrm{L}}+\mathrm{I}_{\text {ref }} \alpha\right)
$$

Similarly, $v_{n+1}=v_{c}\left(t_{n}^{\prime}\right)$. The solution of $v_{c}\left(t_{n}^{\prime}\right)$ is given by

$$
\mathrm{v}_{\mathrm{c}}\left(\mathrm{t}_{\mathrm{n}}^{\prime}\right)=\mathrm{e}^{\alpha \mathrm{t}_{\mathrm{n}}^{\prime}}\left(\mathrm{c}_{3} \cos \beta \mathrm{t}_{\mathrm{n}}^{\prime}+\mathrm{c}_{4} \sin \beta \mathrm{t}_{\mathrm{n}}^{\prime}\right)
$$

Setting $\mathrm{t}=0$ immediately after $\mathrm{S}$ has opened the values of $\mathrm{c}_{3}$ and $\mathrm{c}_{4}$ were determined using equation (14) as,

$$
v_{c}(0)=c_{3}=v_{n} e^{\frac{-t_{n}}{R C}}
$$

It can be seen that

$$
-\mathrm{L}\left(\mathrm{c}_{1} \alpha+\mathrm{c}_{2} \beta\right)=\mathrm{v}_{\mathrm{c}}(0)
$$

Hence equation (15) can be written as

$$
\mathrm{c}_{3}=-\mathrm{L}\left(\mathrm{c}_{1} \alpha+\mathrm{c}_{2} \beta\right)
$$

Using $v_{c}(t)$ from Equation (14) and solving gives

$$
\mathrm{c}_{4}=-\frac{1}{\beta}\left[\alpha \alpha_{\mathrm{c}}(0)-\frac{\mathrm{I}_{\mathrm{ref}}}{\mathrm{C}}\right]
$$

It can be seen that

$$
-\mathrm{L}\left(\mathrm{c}_{2} \alpha-\mathrm{c}_{1} \beta\right)=-\frac{1}{\beta}\left[\alpha \alpha_{\mathrm{c}}(0)-\frac{\mathrm{I}_{\mathrm{ref}}}{\mathrm{C}}\right]
$$

Equation (18) can be written as

$$
\mathrm{c}_{4}=-\mathrm{L}\left(\mathrm{c}_{2} \alpha-\mathrm{c}_{1} \beta\right)
$$

Substitution of $t_{n}{ }^{\prime}$ and also $c_{3}$ and $c_{4}$ in terms of $c_{1}$ and $\mathrm{c}_{2}$ provides $\mathrm{v}_{\mathrm{n}+1}$ as,

$$
\begin{aligned}
\mathrm{v}_{\mathrm{n}+1}= & -\mathrm{Le} \mathrm{e}^{\alpha\left(\mathrm{T}-\mathrm{t}_{\mathrm{n}}\right)}\left[\left(\mathrm{c}_{1} \alpha+\mathrm{c}_{2} \beta\right) \cos \beta\left(\mathrm{T}-\mathrm{t}_{\mathrm{n}}\right)+\left(\mathrm{c}_{2} \alpha-\mathrm{c}_{1} \beta\right)\right. \\
& \left.\left.\sin \beta \mathrm{in}-\mathrm{t}_{\mathrm{n}}\right)\right]
\end{aligned}
$$

The two equations (13) and (21) represent the discrete time mapping of the inductor current and capacitor voltage of the buck-boost converter. Given an initial state $\left(\mathrm{v}_{\mathrm{o}}, \mathrm{i}_{\mathrm{o}}\right)$, 
the mapping in the form presented in the equations (13) and $(21)$ can be iterated to generate the sequence $\left(\mathrm{v}_{1}, \mathrm{i}_{1}\right),\left(\mathrm{v}_{2}\right.$ $\left.i_{2}\right)$----- $\left(v_{n}, i_{n}\right)$. The behaviour of the converter for different values of $I_{\text {ref }}$ is determined from this mapping.

\section{Chaotic Behaviour in Current Mode Controlled Buck-Boost Converter}

The circuit diagram of current mode controlled buckboost converter is shown in Figure 4. The switch is turned $\mathrm{ON}$ and OFF periodically according to the output of a comparator that compares the inductor current $i_{L}$ with a current reference $\mathrm{I}_{\text {ref. }}$ When the switch is $\mathrm{ON}$, the inductor current increases and as it reaches $\mathrm{I}_{\mathrm{ref}}$, the switch is turned OFF, thereby causing the inductor current to ramp down until the next clock arrives.

A MATLAB/SIMULINK simulation model of current programmed buck-boost converter is developed and simulated. The circuit parameters chosen are $\mathrm{V}_{\mathrm{in}}=12 \mathrm{~V}, \mathrm{~L}=1 \mathrm{mH}$, $\mathrm{C}=4 \mu \mathrm{F}, \mathrm{R}=20 \Omega, \mathrm{T}=50 \mu \mathrm{s}, \mathrm{f}_{\mathrm{s}}=20 \mathrm{kHz}$.

The various possible operating regimes of the current programmed buck-boost converter are analyzed with variation of $I_{r e f}$ keeping other parameters fixed and for large values of $\mathrm{I}_{\text {ref }}$, the system is found to exhibit chaos through period doubling.

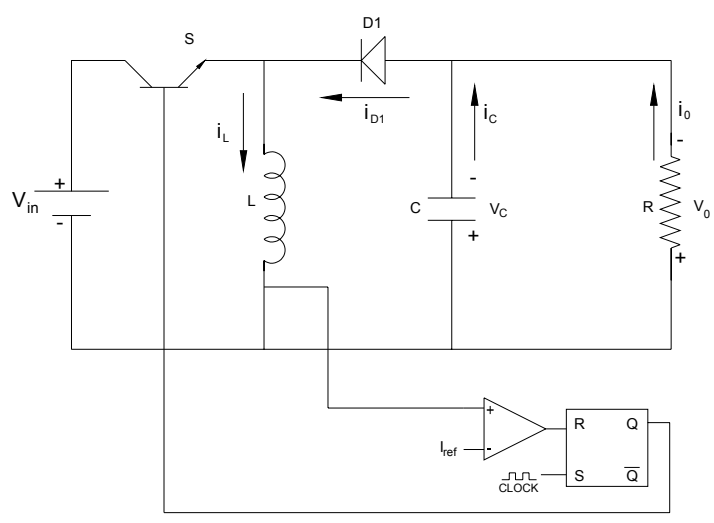

Fig. 4. Circuit diagram of current mode controlled buckboost converter.

\subsection{Period 1 Operation}

With $\mathrm{I}_{\text {ref }}$ set at $1.76 \mathrm{~A}$, the buck-boost converter exhibits fundamental period 1 operation. The simulated and experimental waveforms of capacitor voltage, inductor current and the corresponding phase portrait are shown in Figs. $5,6,7,8$ and 9 respectively.

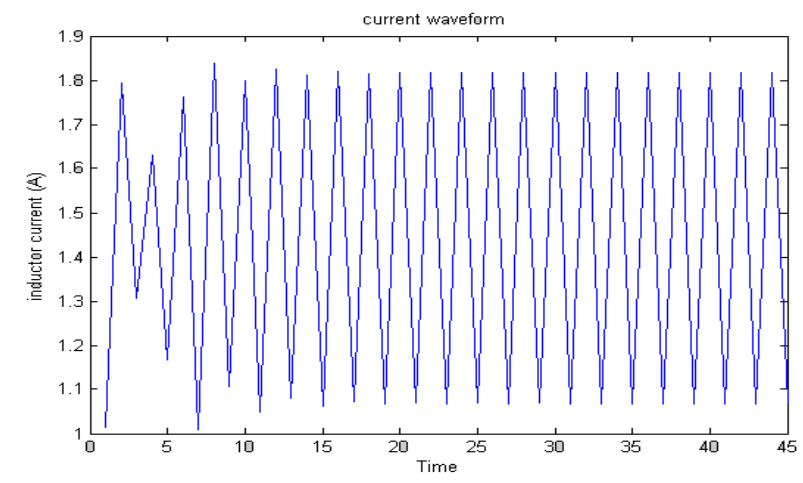

Fig. 5. Simulated inductor current waveform of period 1 operation with $\mathrm{I}_{\text {ref }}=1.76 \mathrm{~A}$.

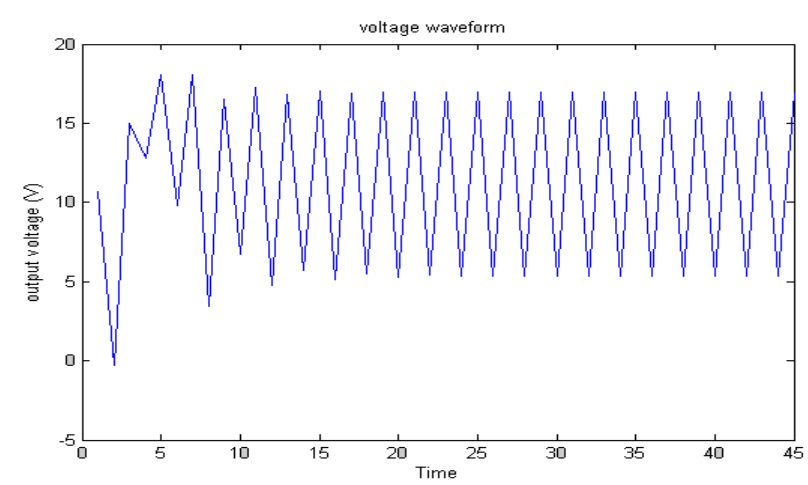

Fig. 6. Simulated capacitor voltage waveform period 1 operation with $\mathrm{I}_{\mathrm{ref}}=1.76 \mathrm{~A}$.

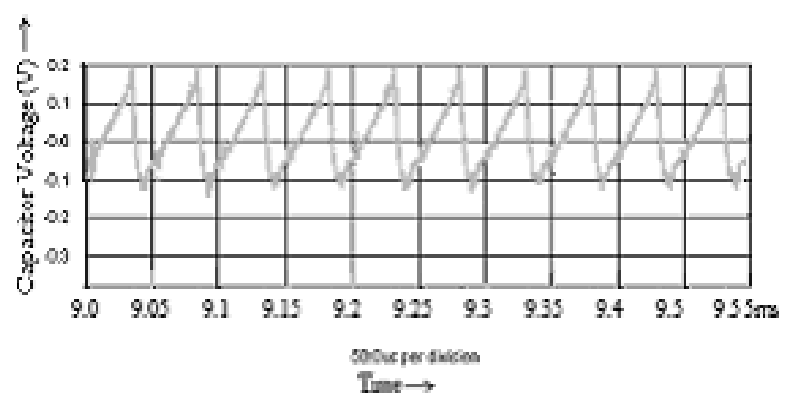

Fig. 7. Experimental capacitor voltage waveform of period 1 operation with $\mathrm{I}_{\mathrm{ref}}=1.76 \mathrm{~A}$.

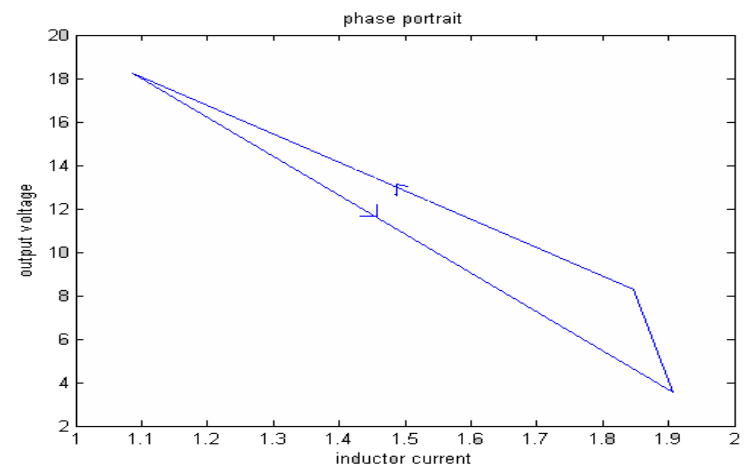

Fig. 8. Simulated phase portrait showing period 1 operation. 


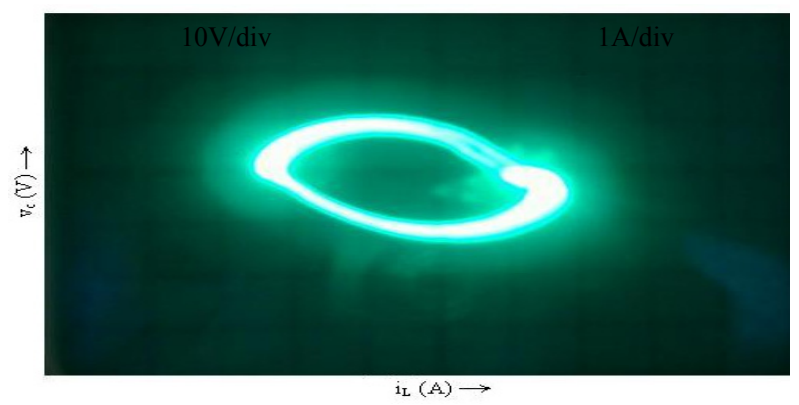

Fig. 9. Experimental phase portrait showing period 1 operation.

\subsection{Period 2 Operation}

When $I_{\text {ref }}$ is increased, period 1 operation is no longer possible. When $\mathrm{I}_{\text {ref }}$ increases beyond a $1.86 \mathrm{~A}$, period of operation doubles itself leading to period $2,4,8$. The doubling occurs in smaller and smaller intervals until, in a finite interval, infinitely many period-doubling occurs like period 2 , period $4,8,16,32 \ldots$ infinity. The simulated and experimental waveforms of capacitor voltage, inductor current and the corresponding phase portrait are shown in Figs. 10, 11, 12, 13 and 14 respectively.

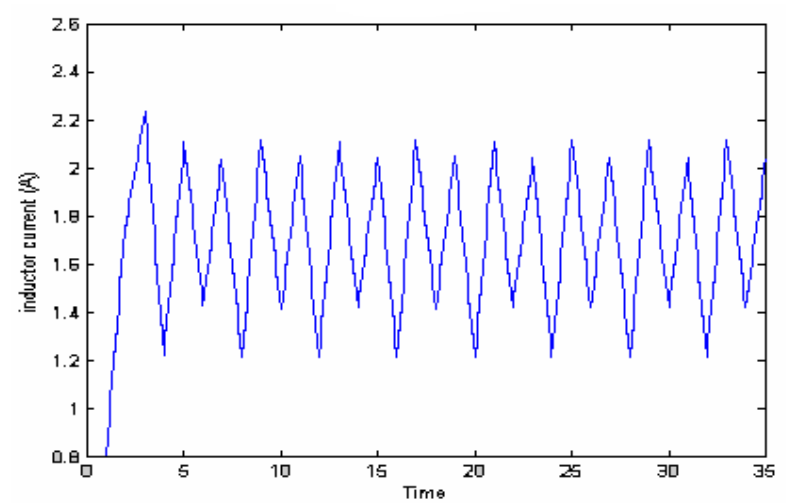

Fig. 10. Simulated Inductor current waveform of period 2 operation with $\mathrm{I}_{\text {ref }}=1.86 \mathrm{~A}$.

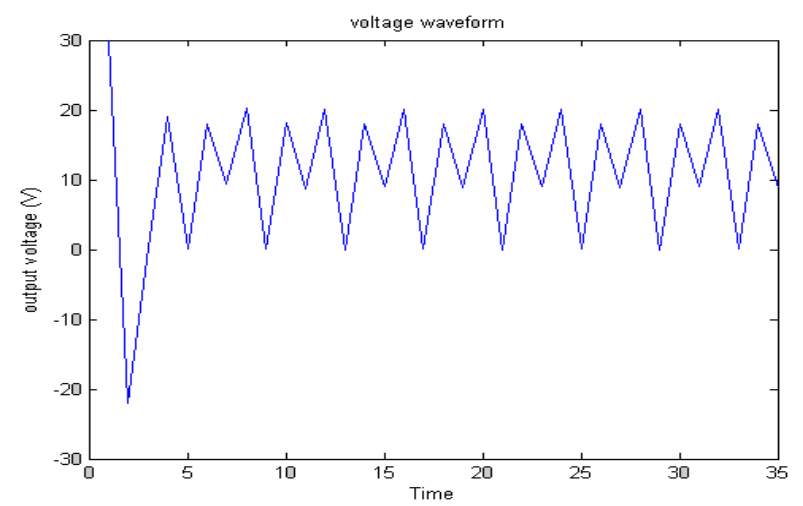

Fig. 11. Simulated capacitor voltage waveform of period 2 operation with $\mathrm{I}_{\text {ref }}=1.86 \mathrm{~A}$.

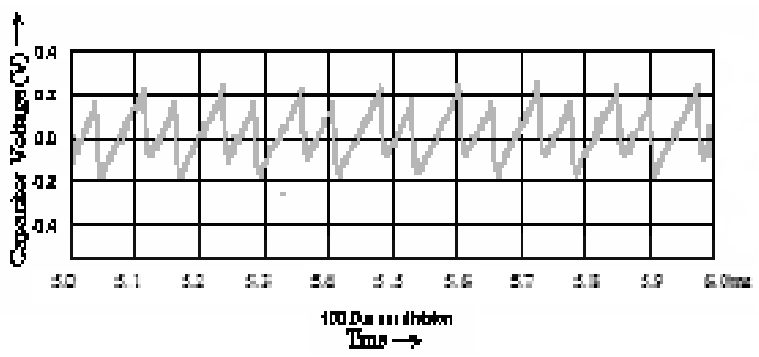

Fig. 12. Experimental capacitor voltage waveform of period 2 operation with $\mathrm{I}_{\text {ref }}=1.86 \mathrm{~A}$.

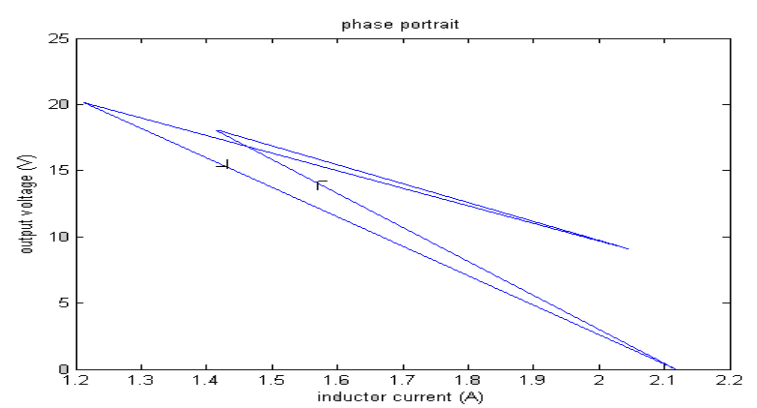

Fig. 13. Simulated phase portrait showing period 2 operation.

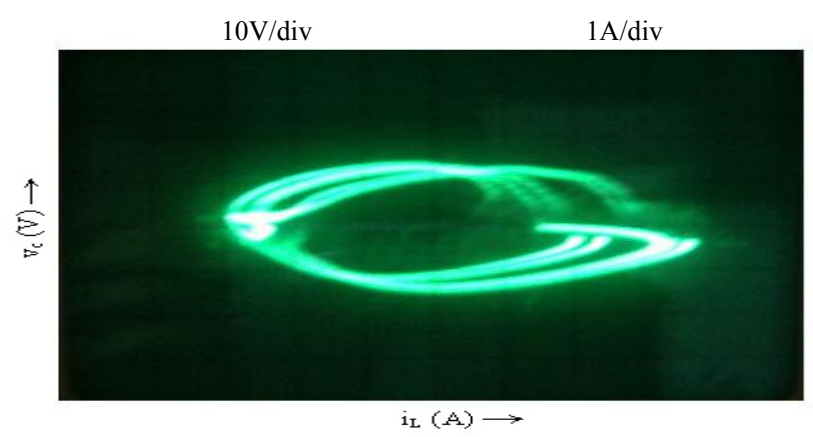

Fig. 14. Experimental phase portrait showing period 2 operation.

\subsection{Period 4 Operation}

With $\mathrm{I}_{\text {ref }}$ set at $2 \mathrm{~A}$, the buck-boost converter exhibits period 4 operation. The simulated and experimental waveforms of capacitor voltage, inductor current are shown in Figs. 15, 16 and 17 respectively.

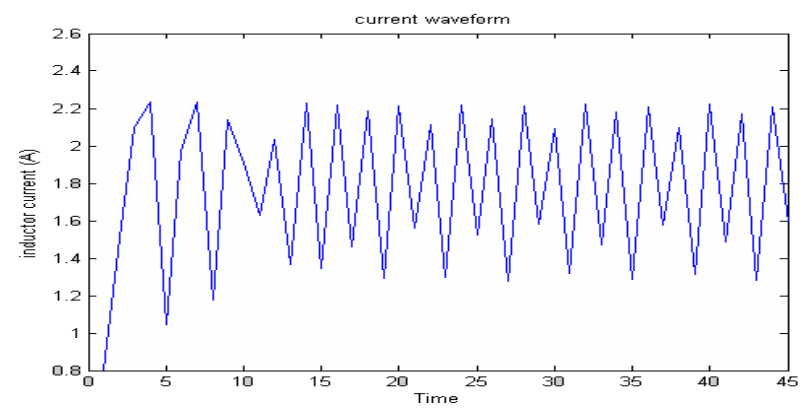

Fig. 15. Simulated inductor current waveform of period 4 operation with $\mathrm{I}_{\mathrm{ref}}=2 \mathrm{~A}$. 


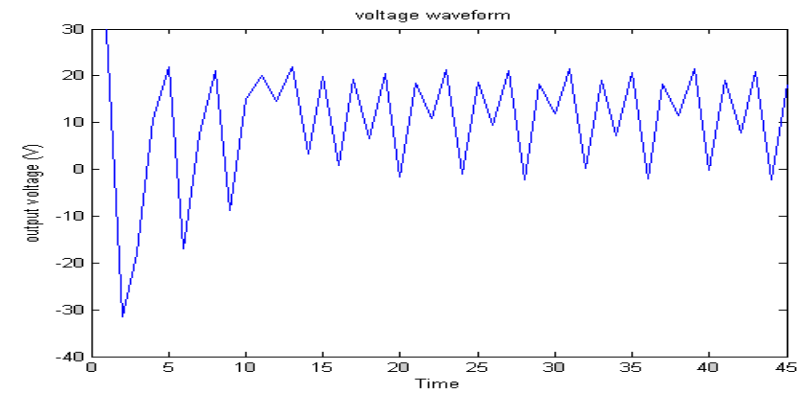

Fig. 16. Simulated capacitor voltage waveform of period 4 operation with $\mathrm{I}_{\mathrm{ref}}=2 \mathrm{~A}$.

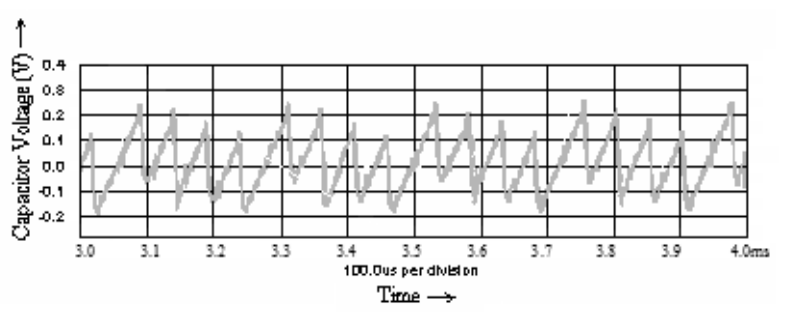

Fig. 17. Experimental capacitor voltage waveform of period 4 operation with $\mathrm{I}_{\text {ref }}=2 \mathrm{~A}$.

\subsection{Chaotic operation}

When the value of $I_{\text {ref }}$ is further increased the converter enters into chaotic regime. The simulated and the experimental waveforms of capacitor voltage and inductor current are shown in Figs. 18, 19 and 20 respectively. The simulated and experimental phase portrait showing chaotic operation has been shown in Figs. 21 and 22.

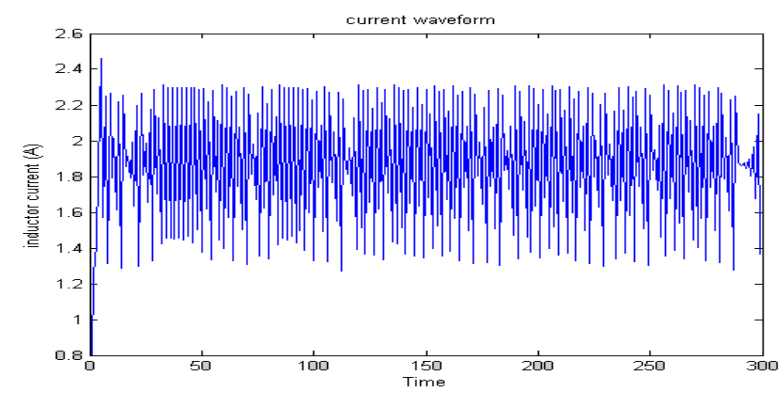

Fig. 18. Simulated inductor current waveform of chaotic operation with $\mathrm{I}_{\text {ref }}=2.21 \mathrm{~A}$.

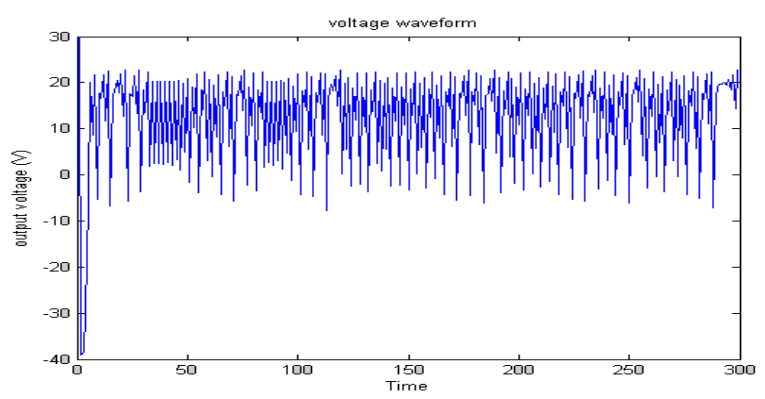

Fig. 19. Simulated capacitor voltage waveform of chaotic operation with $\mathrm{I}_{\mathrm{ref}}=2.21 \mathrm{~A}$.

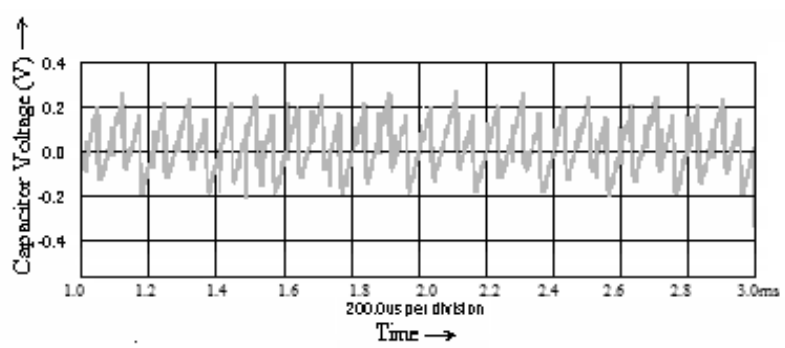

Fig. 20. Experimental capacitor voltage waveform of chaotic operation with $\mathrm{I}_{\mathrm{ref}}=2.21 \mathrm{~A}$.

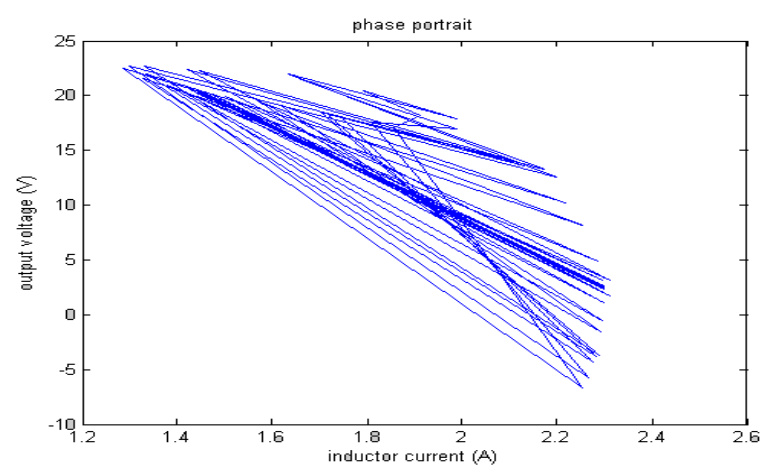

Fig. 21. Simulated phase portrait showing chaotic operation.

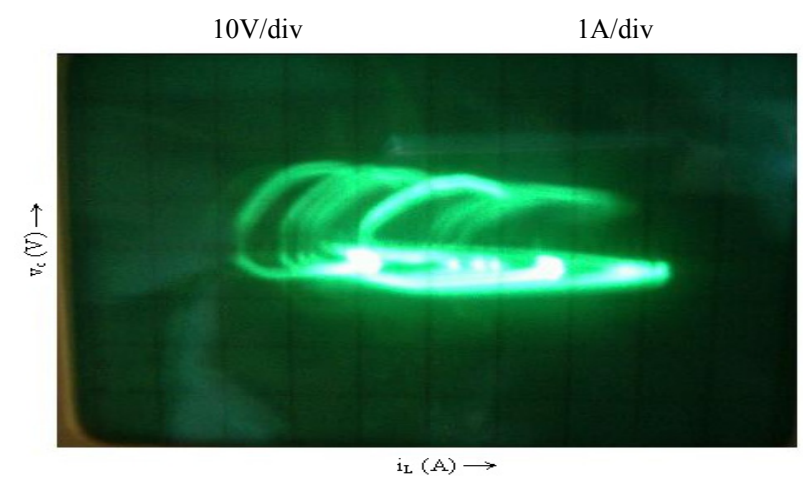

Fig. 22. Experimental phase portrait showing chaotic operation.

The simulation and hardware results show that the buckboost converter exhibits a wide range of non-linear behavior.

\section{Application of Resonant Parametric Perturbation to Control Chaos}

The resonant parametric perturbation method is applied to stabilize the chaotic buck-boost converter. Here, a parameter that strongly affects the converter $\mathrm{I}_{\text {ref }}$ is selected as the perturbing parameter [8] and perturbed $\widetilde{I}_{\text {ref }}$ is given by $\mathrm{I}_{\text {ref }}\left(1+\varepsilon \sin 2 \pi \mathrm{f}_{\mathrm{p}} \mathrm{t}\right)$. Here $\varepsilon$ is the perturbation amplitude set to 0.027 and $\mathrm{f}_{\mathrm{p}}$ is the perturbation frequency and it is set to the switching frequency of $20 \mathrm{kHz}$. The function $\widetilde{\mathrm{I}}_{\text {ref }}=\mathrm{I}_{\mathrm{ref}}\left(1+\varepsilon \sin 2 \pi \mathrm{f}_{\mathrm{p}} \mathrm{t}\right)$ is realized using $\mu \mathrm{A} 741$ op-amp. The implementation of resonant parametric perturbation 
method to control chaos in the current controlled buckboost converter is shown in Fig. 23.

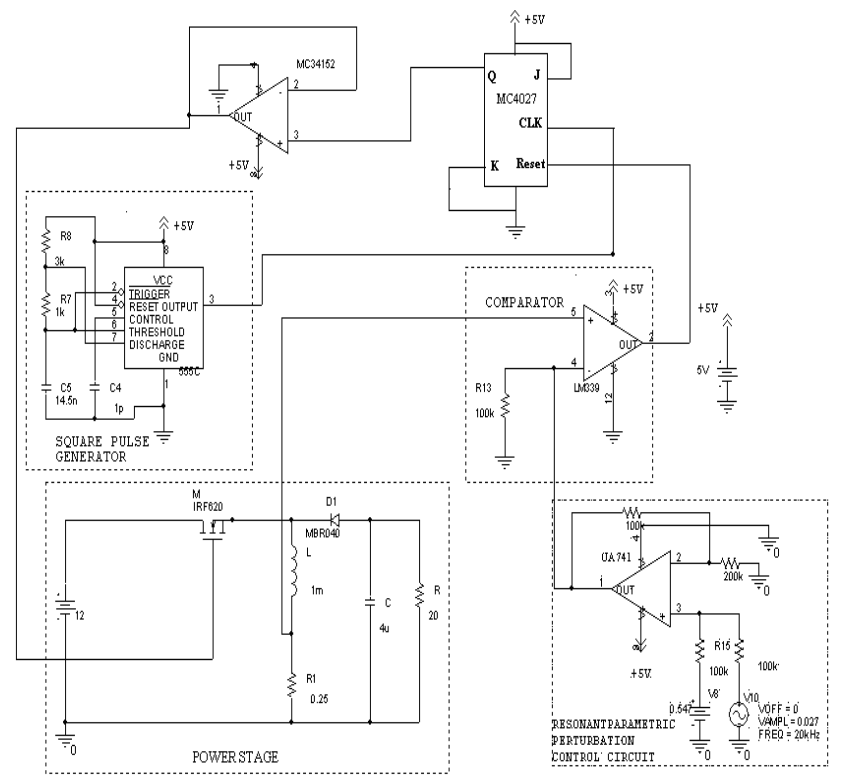

Fig. 23. Circuit of the current mode controlled buck-boost converter implementing resonant parametric perturbation.

The output of the $\mu \mathrm{A} 741$ op-amp which is the perturbed current reference is shown in Fig. 24. The perturbing signal is synchronized with the switching frequency. The chaotic converter is stabilized to operate in period 1 orbit. The experimental capacitor voltage waveform showing the controlled period 1 operation and the corresponding phase portrait are shown in Figs. 25 and 26 respectively.

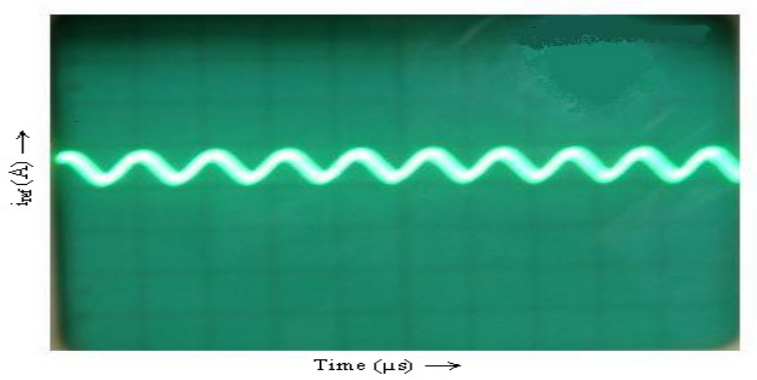

Fig. 24. Experimental waveform of perturbed current reference.

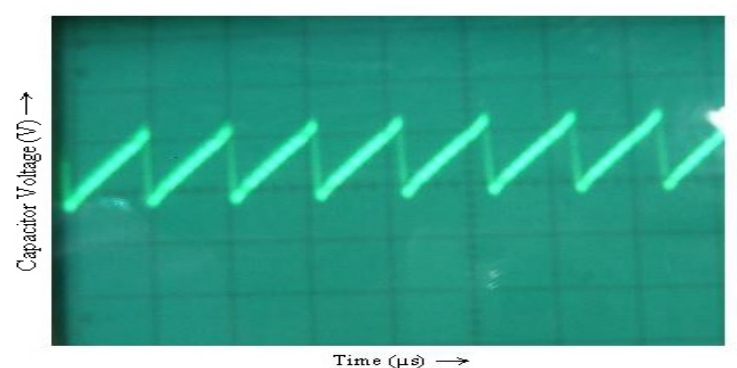

Fig. 25. Experimental capacitor voltage waveform showing controlled period 1 operation with $\mathrm{I}_{\mathrm{ref}}=2.21 \mathrm{~A}$.

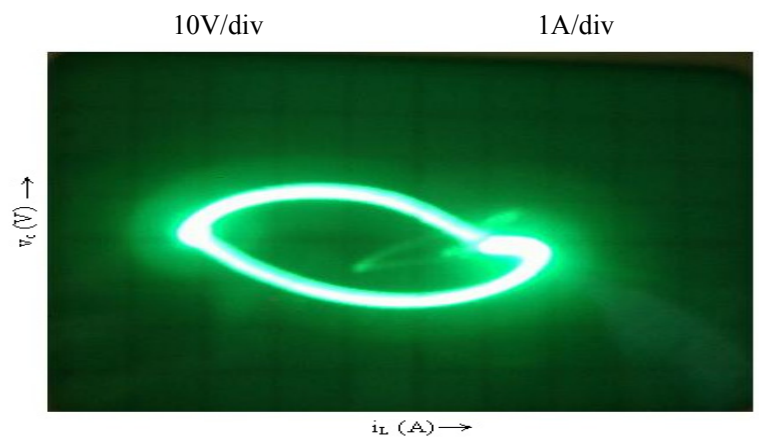

Fig. 26. Phase portrait showing controlled period 1 operation.

\section{Conclusion}

The various possible operating regimes of the current mode controlled buck-boost converter have been discussed and the simulation and experimental results are shown. The simulation results show a good agreement with the experimental waveforms. The resonant parametric perturbation method has been applied to the current programmed buckboost dc-dc converter [9]. The converter has been stabilized to period 1 operation practically.

\section{References}

[1] D.C.Hamill, "Power Electronics: A field rich in nonlinear dynamics," International workshop on Nonlinear Dynamics Electron.Syst., Ireland, July 1995.

[2] J. Deane, D. Hamill, "Instability, Sub harmonics and Chaos in power electronic systems," IEEE Transactions on Power Electronics, 260-267, 1990.

[3] S.Banerjee,G.C.Verghese, "Nonlinear phenomena in power electronics: Attractors," bifurcations, chaos and nonlinear control, IEEE press, 2001.

[4] Y.Zhou, C.K.Tse, S.S.Qiu, F.C.M. Lau, "Applying resonant parametric perturbation to control chaos in the buck dc/dc converter with phase shift and frequency mismatch considerations," International Journal of Bifurcation and Chaos, pp.3459-3471, 2003.

[5] G.Cicogna., "Changing the threshold of chaos by resonant parametric Modulation," Nuova Cim, pp.813815, 1990.

[6] R.Lima, M.Pettini, "Suppression of chaos by resonant parametric perturbations," Physics Review, A41, pp. 726-733, 1990.

[7] J.Wu, M.Liu, P.Yang, "Study of bifurcations and chaos in current mode controlled buck-boost dc-dc converter", Control theory and Applications," pp. 387-394, 2002.

[8] Y.Zhou, H.H.C.Iu, C.K.Tse, J.N.Chen, "Controlling chaos in DC/DC converters using optimal resonant parametric perturbation," IEEE ISCAS'05, Vol.3, pp. 2481-2484, 2005.

[9] Kavitha A. and Uma G., "Analysis and Control of Chaos in Current Controlled Buck Boost DC-DC 
Converter by Resonant Parametric Perturbation Method," Proceedings of Applied Power Electronics Conference and Exposition APEC'08, 24-28 $8^{\text {th }}$ February, Austin, Texas University, USA, pp.323-327, 2008.

\section{Appendix A}

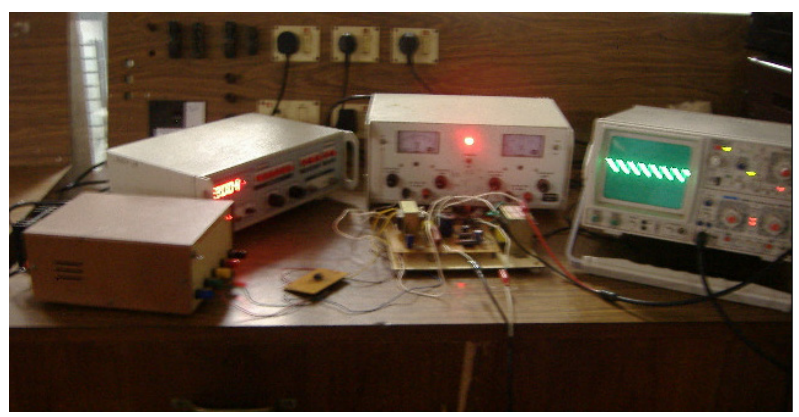

Fig. 27. Experimental Setup.

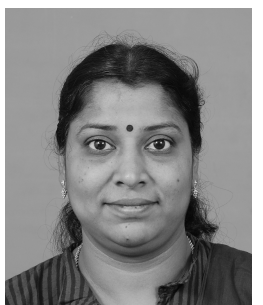

Anbukumar Kavitha She has been awarded the Master's degree from Indian Institute of Madras in the year 2002. She is a member of ISTE. Presently she is working as a Lecturer, EEE department, College of Engineering, Guindy, Anna University, Chennai, Tamilnadu, India. Her areas of interest are dc-dc converters, Chaos and Bifurcations.

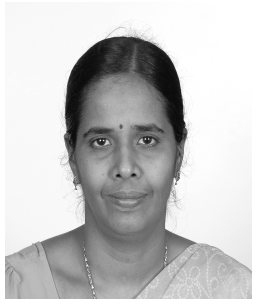

Govindarajan Uma She completed Ph.D degree in dc-dc converters from Anna University. Presently she is working as an Assistant Professor, EEE department, College of Engineering, Guindy, Anna University, Chennai, Tamilnadu, India. Her areas of interest are Power Quality, Resonant Converters, and Ma-

trix Converters. 